Enfermagem Brasil 2018;17(5):426-7

\title{
EDITORIAL \\ Envelhecimento e uso de psicotrópicos
}

Camila Garcel Pancote, D.Sc. ${ }^{\star}$, Natália Sperli Geraldes Marin dos Santos Sasaki**, Maria de Lourdes Sperli Geraldes Santos, D.Sc. ${ }^{* *}$, Zaida Aurora Sperli Geraldes Soler, D.Sc. ${ }^{* \star \star *}$

*Graduada em Farmácia, doutora em Fármaco e Medicamentos pela Faculdade de Ciências Farmacêutica de São Paulo - USP, Docente do curso de Medicina da União das Faculdades dos Grandes Lagos - Unilago, ${ }^{* *}$ Graduada em enfermagem, enfermeira obstetra docente $e$ coordenadora do curso de enfermagem da União das Faculdades dos Grandes Lagos Unilago, Docente do programa de mestrado em enfermagem da FAMERP, ${ }^{* * *}$ Enfermeira, doutora pelo Programa Interunidades de Doutoramento em Enfermagem pela Escola de Enfermagem de Ribeirão Preto - USP, professora adjunta IV da Faculdade de Medicina de São José do Rio Preto - SP (FAMERP) e docente da graduação e pós-graduação em enfermagem da FAMERP, ${ }^{* * * * * *}$ Obstetriz, enfermeira, docente e orientadora de graduação e pós-graduação e pesquisadora do ensino e exercício da Enfermagem no Brasil

Correspondência: E-mail: Camila Garcel Pancote: camilapancote@hotmail.com; Natália Sperli Geraldes Marin dos Santos Sasaki: nsperli@gmail.com; Maria de Lourdes Sperli Geraldes Santos: Isperli@yahoo.com.br; Zaida Aurora Sperli Geraldes Soler: zaidaaurora@gmail.com

O envelhecimento humano é um processo universal, complexo e sua progressão é consequência do aumento da longevidade e diminuição das taxas de natalidade [1,2].

A população idosa no Brasil vem crescendo de forma significativa, passando de $9,8 \%$ em 2005 para 14,3\% em 2015, o que representa um crescimento anual por volta de $1,0 \%$ do total da população brasileira (estimada em 204,9 milhões no ano de 2015). Neste mesmo período, a parcela de pessoas de zero a 14 anos no total da população diminuiu de $26,5 \%$ para $21 \%$ e de 15 a 29 anos, de $27,4 \%$ para $23,6 \%$. Neste contexto, o Brasil caminha para se tornar um país de idosos no ano de 2030, considerando estimativas do IBGE para este ano, de que 0 país contará com predomínio de idosos em relação ao grupo de crianças e adolescentes até 14 anos de idade [2-4].

A complexidade do processo de envelhecimento está pautada no fato que essa transição etária vem acompanhada de alterações biológicas, cognitivas e motoras, além de mudanças sociais, como, por exemplo, o afastamento do indivíduo do mercado de trabalho, além da relação com o aumento das doenças crônicas não transmissíveis, que muitas vezes levam a incapacidade. As doenças neurodegenerativas e depressão estão entre as mais citadas neste grupo etário e esta última apresenta maior incidência em mulheres, segundo relatos na literatura. Muitos desses indivíduos apresentam problemas emocionais, que não são levados em consideração pela equipe de saúde, continuamente por despreparo, considerando a incipiência das políticas públicas voltadas para o envelhecimento [2,4-6].

Ressalta-se que nessa fase da vida é muito comum o pensamento em torno da morte e o sentimento de incapacidade, impotência devido ao afastamento do trabalho em razão das doenças crônicas, desempenho sexual comprometido, inúmeras perdas durante a vida, dentre outros fatores que, aliados a dificuldade do manejo do processo saúde doença do idoso pelo serviço de saúde, principalmente daquela em idade mais avançada, contribuem para prolongar seu sofrimento, a ponto de motivá-lo a atentar contra a própria vida, a fim de aliviar sua dor e, muitas vezes, diminuir o peso que causa em sua família $[1,2,7]$.

Com base neste cenário, o uso dos psicotrópicos nesta população tornou-se rotineiro, sendo estes os medicamentos mais prescritos entre os idosos. Os antidepressivos lideram o ranking de prescrições, em virtude da maior incidência de episódios depressivos entre estes indivíduos. Os benzodiazepínicos também ocupam locais de destaque em número de prescrições, já que distúrbios do sono é motivo de grande parte das reclamações por esta população. Estes medicamentos atuam no sistema nervoso central e em alguns pacientes proporcionam maior alívio dos desconfortos relatados, como depressão, ansiedade e insônia. Entretanto o uso incorreto e abusivo dessa classe de fármacos, somado às possíveis interações com outros fármacos, tais como anti-hipertensivos, hipoglicemiantes, entre outros, pode trazer riscos potenciais à saúde do idoso, bem como intoxicação e óbito [8-11]. 
Nesse sentido, é essencial o desenvolvimento de estratégias, programas e ações orientadas à prescrição racional de psicotrópicos aos idosos, considerando que alterações farmacocinéticas e farmacodinâmicas nessa população devem ser relevantes ao planejamento terapêutico. O acompanhamento desses pacientes é essencial e deve ser motivo de grande preocupação por parte dos profissionais da saúde, a fim de promover qualidade de vida e bemestar para essa população.

1. Miranda GMD, Mendes ACG, Silva ALA. O envelhecimento populacional brasileiro: desafios e consequências sociais atuais e futuras. Rev Bras Geriatr Gerontol 2016;19(3):507-19.

2. Pedrosa B, Duque R, Martins R. Suicídio no idoso - o antecipar da morte. Psilogos 2016;14(1):50-56.

3. Brasil. Instituto Brasileiro de Geografia e Estatística (IBGE). Síntese de indicadores sociais: uma análise das condições de vida da população brasileira, 2016. [citado 2018 Out 2018]. Disponível em: https://biblioteca.ibge.gov.br/visualizacao/livros/liv98965.pdf.

4. Marques JFS, De Sá SC, Freitas-Filho W, Espírito-Santo LR, Prince KA, Oliveira MVM. Transtorno depressivo maior em idosos não institucionalizados atendidos em um centro de referência. Arq Ciênc Saúde 2017;24(4):20-24.

5. Abi-Ackell MM, Lima-Costall MFL, Castro-Costall E, Loyola-Filho Al. Uso de psicofármacos entre idosos residentes em comunidade: prevalência e fatores associados. Rev Bras Epidemiol 2017;20(1):57-69.

6. Noia AS, Secoli SR, Duarte YAO, Lebrão ML, Lieber NSR. Fatores associados ao uso de psicotrópicos por idosos residentes no Município de São Paulo. Rev Esc Enferm USP 2012;46(Esp):38-43.

7. Carvalho ILN, Lôbo APA, Aguiar CAA. A intoxicação por psicofármacos com motivação suicida: uma caracterização em idosos. Rev Bras Geriatr Gerontol 2017;20(1):134-42.

8. Naloto DCC, Lopes FC, Barberato-Filho S, Lopes LC, Del-Fiol FS, Bergamaschi CC. Prescrição de benzodiazepínicos para adultos e idosos de um ambulatório de saúde mental. Ciênc Saúde Coletiva 2016;21(4):1267-76.

9. Oliveira LPBA, Santos SMA. Uma revisão integrativa sobre o uso de medicamentos por idosos na atenção primária à saúde. Rev Esc Enferm USP 2016;50(1):167-79.

10. Prado MAMB, Francisco PMSB, Barros MBA. Uso de medicamentos psicotrópicos em adultos e idosos residentes em Campinas, São Paulo: um estudo transversal de base populacional. Epidemiol Serv Saude 2017;26(4):747-58.

11. Rodrigues MCS, Oliveira C. Drug-drug interactions and adverse drug reactions in polypharmacy among older adults: an integrative review. Rev Latinoam Enferm 2016;24:e2800. [citado 2018 Out 14]. Disponível em: http://www.scielo.br/pdf/rlae/v24/pt_0104-1169-rlae-24-02800.pdf. 